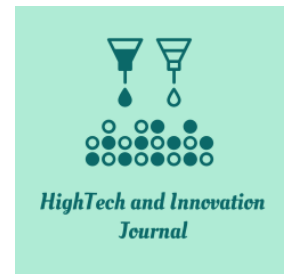

ISSN: $2723-9535$

\title{
An Integrated Approach of Multi-Criteria Decision Making to Determine the Most Habitable Planet
}

\author{
Gizem Gunaydin ${ }^{1 *}$, Gamze Duvan ${ }^{1}$, Eren Ozceylan ${ }^{1}{ }^{1}$ \\ ${ }^{1}$ Industrial Engineering Department, Gaziantep University, Gaziantep 27100, Turkey.
}

Received 09 December 2021; Revised 08 February 2022; Accepted 14 February 2022; Available online 19 February 2022

\begin{abstract}
Every planet in the universe has its own characteristics. These features make the planets different among themselves. For this reason, all the different properties of the planets must be evaluated at the same time when determining habitable planets. This situation requires a multi-criteria decision making (MCDM) approach. In this study, a list of habitable planets (nine planets and the Moon) has been considered. Seventeen different criteria such as mass, gravity, diameter, density, escape velocity, rotation time, day of length, distance from the sun, perihelion, aphelion, orbital period, orbital velocity, orbital inclination, orbital eccentricity, obliquity to orbit, mean temperature, and number of satellites are taken into account. The weights of criteria are determined with DEMATEL (The Decision Making Trial and Evaluation Laboratory) by analyzing the interactions among criteria. Orbital inclination is the criterion with the highest weight, and the criterion with the lowest weight is the number of satellites. After weighting the criteria with DEMATEL, VIKOR (VIseKriterijumska Optimizacija I Kompromisno Resenje) and TOPSIS (Technique for Order Preference to Similarity to Ideal Solution) approaches are used to rank the planets. According to the TOPSIS, Earth is ranked first, Venus ranked second and Mercury ranked third in the order of the most habitable planets. According to the VIKOR method, Earth is ranked first, Mars is ranked second, and Mercury is ranked third in the order of the most habitable planets. Finally, the same calculations are considered with equal weights and the results are discussed.
\end{abstract}

Keywords: Habitable Planets; DEMATEL; TOPSIS; VIKOR; Multiple-criteria Decision Analysis.

\section{Introduction}

There are many planets in the solar system. Although Earth is currently known as the only planet with life, people have sought different habitats for many years. Whether there is life on the moon and other planets has always been a matter of wonder. Certain criteria that Earth has for the existence of life are important. Many criteria, such as a planet's mass, gravity, distance from the sun, and period speed, are criteria that affect life. These criteria that every planet has are unique. The multi criteria decision making (MCDM) methods should be used to analyse the planets in terms of habitability according to these criteria.

In this study, Mercury, Venus, Earth, Mars, Jupiter, Saturn, Uranus, Neptune, and the Moon are taken into consideration as alternatives. A total of 17 different criteria, such as mass, diameter, distance to the sun, average temperature, gravity, and orbital velocity, were weighted using the DEMATEL method. Using these weights, the TOPSIS and VIKOR methods were applied and the planets were ranked. At the same time, the same procedures were done by taking the weights equally.

* Corresponding author: gizem.gunaydin44@gmail.com

doi http://dx.doi.org/10.28991/HIJ-2022-03-02-04

$>$ This is an open access article under the CC-BY license (https://creativecommons.org/licenses/by/4.0/).

(C) Authors retain all copyrights. 
This study has four main objectives. The first aim is to weight the criteria that affect the habitability of planets with the DEMATEL method. The second aim is to rank the planets by using the TOPSIS and VIKOR methods, using the calculated weights. The third goal is to take the weights of the criteria equally and analyse them to observe the effects of the criteria weights. The last aim is to show the applicability of MCDM methods in these areas.

\section{Literature Review}

MCDM methods are used in many different areas. Some of these are given in Table 1. However, MCDM studies on space and planets are rarely encountered. One of the MCDM applications in space problems is done by Yücenur and Subaş1 (2019) [1]. They selected the most appropriate city in Turkey for the space shuttle launching ramp. In their integrated approach, the SWARA method is used in the first phase of the solution for determining the criteria' importance weights, and the WASPAS method is used for selecting the best alternative. However, a paper that uses MCDM approaches regarding the ranking of the habitability of the planets has not been observed.

Table 1. Literature Review

\begin{tabular}{|c|c|c|}
\hline Method & Reference & Problem \\
\hline \multirow{6}{*}{ DEMATEL } & Shieh et al. (2010) [2] & Identifying the key success factors of hospital service quality. \\
\hline & Abbasi et al. (2013) [3] & Evaluation of risks in knowledge-based networks. \\
\hline & Ada et al. (2011) [4] & Evaluation of factors affecting flexible production systems. \\
\hline & Aksakal and Dağdeviren (2010) [5] & Personnel selection. \\
\hline & Dey et al. (2012) [6] & Supplier selection. \\
\hline & Karaatlı et al. (2016) [7] & Performance appraisal in human resources. \\
\hline \multirow{6}{*}{ TOPSIS } & Ömürbek and Kınay (2013) [8] & Financial performance assessment in airline transport sector. \\
\hline & Uygurtürk and Korkmaz (2012) [9] & Financial performance assessment in metal industry. \\
\hline & Yurdakul and İç (2003) [10] & Performance measurement and analysis of Turkish automotive companies. \\
\hline & Boran et al. (2009) [11] & Supplier selection. \\
\hline & Tırmıkçığlu (2010) [12] & Establishment selection in banking sector. \\
\hline & Kahriman et al. (2015) [13] & Selection of a communication satellite manufacturer using MCDM methods \\
\hline \multirow{4}{*}{ VIKOR } & Tadic et al. (2014) [14] & City logistics concept selection. \\
\hline & Hsu et al. (2012) [15] & Vendor selection for conducting the recycled material. \\
\hline & Görener (2011) [16] & Selection of ERP software. \\
\hline & Dinçer and Görener (2011) [17] & Performance evaluation in service industry. \\
\hline
\end{tabular}

\section{Applied MCDM Methodologies}

Multi-criteria decision making (MCDM) is a sub-branch of decision sciences. It is based on the process of modeling and analyzing the decision process according to the criteria. Applied three MCDM approaches are described in this section.

\subsection{DEMATEL Method}

DEMATEL is a comprehensive method that establishes and analyses the causality relationship between complex factors in a structural model [18-20] and was developed by the Genoa Battele Institute to analyse complex world problems. The steps of DEMATEL are given [21]:

Step 1: Relationships between criteria are determined by the expert group using the binary comparison scale in Table 2. The numerical values show to what extent one criterion affects another.

Table 2. Binary Comparison Scale

\begin{tabular}{cc}
\hline Numerical Value & Definition \\
\hline 0 & Ineffective \\
1 & Low Effective \\
2 & Moderate Effective \\
3 & High degree Effective \\
4 & Very High Degree Effective \\
\hline
\end{tabular}


Step 2: In case the number of experts evaluating the criteria is more than one, the arithmetic average of the points awarded is taken. These values are then placed in the matrix (Equation 1) and an asymmetric matrix with diagonals " 0 " is obtained.

$X=\left[\begin{array}{ccc}0 & \cdots & X 1 n \\ \vdots & \ddots & \vdots \\ X n 1 & \cdots & 0\end{array}\right]$

Step 3: After the direct relationship matrix is obtained, the largest of each row and column sum is found as Equation 2 is shown.

$\mathrm{S}=\max \left(\max \sum_{j=1}^{n} X i j, \sum_{j=1}^{n} X i j\right)$

Then, the normalized direct relation matrix $(C)$ is formed by dividing each element of the matrix by the value of "s" as shown in Equation 3.

$\mathrm{C}=\frac{X}{S}$

Step 4: As can be seen in Equation 4, the matrix $\mathrm{C}$ is removed from the identity matrix, the inverse is taken and multiplied by the $\mathrm{C}$ matrix again.

$\lim _{H \rightarrow \infty} C+C^{2}+C^{3}+\cdots+C^{H} \quad \mathrm{~F}=\mathrm{C}+C^{2}+C^{3}+\cdots C^{H}=C(1-C)^{-1}$

Thus, the total relationship matrix (F) equation (Equation 4) is obtained.

Step 5: In this step, in order to determine the affecting and affected factor groups and to calculate the net effect degrees, the total relation matrix $(\mathrm{F})$ is determined and the row and column totals are found. These values obtained for each criterion: Each row sum $\left(D_{i}\right)$ means that the criterion affects other criteria directly or indirectly, each column sum $\left(R_{i}\right)$, on the other hand, indicates the sum of direct or indirect effects of the criterion from other criteria. $D_{i}+R_{i}$ for each criterion, the total effect value sent and received, $D_{i}+R_{i}$ indicates the importance of criteria in the system. For each criterion, $D_{i}-R_{i}$ shows the total effect of the criterion on the system. $D_{i}-R_{i}$ value is defined as affecting if it is positive, affected as affected if it is negative.

Step 6: At this stage, after the threshold value of the matrix is determined, the effect-oriented scatter graph is drawn. Criteria above the threshold value are determined as affecting and the direction of impact is indicated by an arrow in the diagram. The situation that any criterion affects itself is also shown in the diagram.

Step 7: In order to obtain the criterion weights, the sum of $D_{i}+R_{i}$ 's squared and $D_{i}-R_{i}$ squared is taken into the root (Equation 5).

$W_{i a=\sqrt{\left(D_{i}+R_{i}\right)^{2}+\left(D_{i}-R_{i}\right)^{2}}}$

Then each weight is divided by the sum of the weights in Equation 6.

$W_{\mathrm{i}}=\frac{W_{i a}}{\sum_{i=1}^{n} W_{i a}}$

Thus, the criterion weights are found.

\subsection{TOPSIS Method}

Technique for Order Preference by Similarity to an Ideal Solution (TOPSIS) method was developed by Hwang and Yoon (1981) [22]. TOPSIS is a MCDM technique that can be applied directly on data without qualitative conversion to a decision problem consisting of $n$ alternatives and $m$ criteria. The steps of TOPSIS approach are given below.

Step 1: The goals and evaluation criteria of the problem are determined.

Step 2: Decision matrix (Equation 7$)$ is created. $N$ number of alternatives $(a 1, a 2, \ldots$ an) are listed one under the other and the properties of the criteria alternatives $(y 1 k, y 2 k, \ldots y n k)$ are listed.

$\mathrm{D}=\left[\begin{array}{ccc}y 11 & \cdots & y 1 n \\ \vdots & \ddots & \vdots \\ y n 1 & \cdots & y n k\end{array}\right]$

Step 3: Normalization process is done. The normalized matrix (Equation 8) is obtained by taking the sum of squares and roots of the criterion values in the created decision matrix. 
$r_{i j}=\frac{y i j}{\sqrt{\sum_{i=1}^{n} y_{i j}^{2}}} i=1,2,3, \ldots n \quad j=1,2,3, \ldots k \quad \mathrm{R}=\left[\begin{array}{ccc}r 11 & \cdots & r 1 n \\ \vdots & \ddots & \vdots \\ r n 1 & \cdots & r n k\end{array}\right]$

For the benefit criterion:

$R_{i j}=\frac{X_{i j}-X_{j \min }}{X_{j \max }-X_{j \min }}$

For the cost criterion:

$R_{i j}=\frac{X_{\text {jmax }}-X_{i j}}{X_{j \max }-X_{j \min }}$

Step 4: Weighting the normal matrix (Equation 11) creates the $V$ matrix. $V$ matrix is formed by multiplying the normalized matrix created for the purpose by $w_{j}$, which is the weight score of the criteria.

$\mathrm{V}=\left[\begin{array}{ccc}V 11 & \cdots & V 1 n \\ \vdots & \ddots & \vdots \\ V n 1 & \cdots & V n k\end{array}\right]$

Step 5: After obtaining the weighted normalized matrix, action is taken in line with the purpose of the problem while determining the ideal solution values. If the goal is maximization, the maximum value in the column is the ideal solution value.

The minimum values for the same column are negative ideal solution values. If the aim is minimization depending on the criterion property, the values obtained will be the opposite. In other words, the positive ideal solution value according to the minimization problem will be the minimum values in each column. Negative ideal solution values are the maximum values in the column (Equation 12).

\section{Ideal Solution Values;}

$A^{*}=\left\{\max _{j} V_{i j} \mid j=1, \ldots, p ; i=1, \ldots m\right\}$

$A^{*}=\left\{V_{1}^{*}, V_{2}^{*}, \cdots V_{n}^{*}\right\}$ shows the maximum values in each column.

\section{Negative Ideal Solution Values;}

$A^{-}=\left\{\min _{i} V_{i j}\right\}$

$A^{-}=\left\{V_{1}^{-}, V_{2}^{-}, \cdots V_{n}^{-}\right\}$shows (Equation 13) in the minimum values in each column.

Step 6: The separation measures of the alternatives are calculated. The distance of each alternative to the ideal solution is calculated with the Euclidian approach (Equations 14 and 15).

$S_{i}^{*}=\sqrt{\sum_{j=1}^{n}\left(V_{i j}-V_{1}^{*}\right)^{2}}$
$S_{i}^{-}=\sqrt{\sum_{j=1}^{n}\left(V_{i j}-V_{1}^{-}\right)^{2}}$

Step 7: The decision to calculate the relative proximity to the ideal solution. The relative proximity of the points to the ideal solution is benefited from the distance from the ideal points.

Ideal solution $C_{i}^{*}$ (Equation 16) is indicated by;

$C_{i}^{*}=\frac{S_{i}^{-}}{S_{i}^{-}+S_{i}^{*}}$

Calculated with $C_{i}^{*}$ value takes value in the range of [0,1], and the closer to 1 , the positive ideal indicates that it approaches the solution and approaches to the negative ideal solution as it approaches 0 .

\subsection{VIKOR Method}

The VIKOR method, which consists of the initials of the Serbian phrase "VIseKriterijumska Optimizacija I Kompromisno Resenje", means multi-criteria optimization and compromise solution [17, 23]. It reached international recognition in 2004 thanks to the work of Opricovic and Tzeng (2004) [24]. The VIKOR method was developed for multi-criteria optimization of complex systems. The method mainly aims to find a compromise solution in the light of alternatives and within the scope of evaluation criteria [16]. The steps of VIKOR are given below. 
Step 1: Best for each criterion $f_{i}^{*}$ and the worst $f_{i}^{-}$. Best values are determined and $i=1,2,3, n$. It is defined as. If $i$ criterion is a utility criterion:

$f_{i}^{*}=\max _{j} f_{i j} \quad f_{i}^{-}=\min _{j} f_{i j}$

It is expressed in the (Equation 17) form.

Step 2: Normalization process: Normalization process is performed in order to make sense and compare values in different units that make up the decision matrix. It is the normalization linear type used in the VIKOR method. The decision problem consisting of $\mathrm{m}$ alternatives and $\mathrm{n}$ criteria is transformed into an $\mathrm{R}$ normalization matrix of $m \mathrm{x} n$ type with the following formula (Equation 18).

$R_{i j}=\frac{f_{j}^{*}-x_{i j}}{f_{j}^{*}-f_{j}^{-}}$

Step 3: Weighting the normalized matrix: If the decision maker attaches different importance to the criteria that make up the alternatives, multiply the columns of the $\mathrm{R}$ matrix obtained at this stage by the weights $w_{i}$, and the weighted normalized matrix V (Equation 19) is obtained.

$V_{i j}=r_{i j} \times w_{j}$

Step 4. Calculation of $S_{i}$ and $R_{i}$ values: $S_{i}$ and $R_{i}$ values are calculated for the criteria $(j=1,2, \ldots n) . S_{i}$ is the i. the average score for the alternative (Equation 20), $R_{i}$ represents the worst score (Equation 21).

$S_{i}=\sum_{j=1}^{n} w_{j} \frac{f_{j}^{*}-x_{i j}}{f_{j}^{*}-f_{j}^{-}}$

$R_{i}=\max \left(w_{j} \frac{f_{j}^{*}-x_{i j}}{f_{j}^{*}-f_{j}^{-}}\right)$

Step 5: Calculation of $\boldsymbol{O}_{\boldsymbol{i}}$ values: Using $S_{i}$ and $R_{i}$ values calculated earlier in this step,

$S^{*}=\min S_{i} \quad S^{-}=\max _{i} \quad R^{*}=\min R_{i} \quad R^{-}=\max _{i}$

values are calculated (Equation 22). Calculation of the value of $Q_{i}$ is shown in Equation (23).

$Q_{i}=v \frac{\left(S_{j}-S^{*}\right)}{\left(S^{-}-S^{*}\right)}+(1-v) \frac{\left(R_{j}-R^{*}\right)}{\left(R^{-}-R^{*}\right)}$

It is calculated by equality. While the $v$ parameter used in the equation shows the maximum group benefit, the value ( 1 $-v)$ indicates the minimum regret of opposing views $(v=0.5)$.

Step 6: Listing the alternatives and checking the conditions: $Q_{i}, S_{i}$ and $R_{i}$ values are listed separately and three different ordered lists of alternatives are obtained. After this process, it is checked whether the alternative with the value of $Q_{i}$ satisfies the following two conditions in order to check the accuracy of the ordering;

Condition 1: Acceptable Advantage: Among the alternatives listed according to $Q_{i}$ values, the 1st place alternative $A^{1}$ and the second place being $A^{2}$ alternative (Equation 24), eligible advantage,

$Q\left(A^{2}\right)-Q\left(A^{1}\right) \geq D Q$

$\mathrm{DQ}=\frac{1}{m-1}$

This parameter calculated with the Equation 25 depends on the number of alternatives and $m$ is the number of alternatives.

Condition 2: Acceptable Stability Condition: $Q_{i}$ values are when ranked, $A^{1}$ alternative takes the first place and $S$ is the best alternative that takes the minimum value according to $R$ values. In this case, the consensus solution is stable in decision making.

\section{Data Collection}

Planets have unique properties for different criteria. By taking 9 planets (Mercury, Venus, Earth, Mars, Saturn, Jupiter, Uranus, Neptune and Pluto) and Moon as alternatives, 17 (mass, diameter, density, gravity, escape velocity, rotation period, length of day, distance from sun, perihelion, aphelion, orbital period, orbital velocity, orbital inclination, orbital eccentricity, obliquity to orbit, mean temperature, number of moon) different criteria were evaluated and analyzed. Data on the planets are given in Table $3[25,26]$. 
Table 3. Planetary Fact Sheet - Metric

\begin{tabular}{|c|c|c|c|c|c|c|c|c|c|c|}
\hline Criteria & Mercury & Venus & Earth & Moon & Mars & Jupiter & Saturn & Uranus & Neptune & Pluto \\
\hline Mass $\left(10^{24}\right) \mathrm{kg}$ & 0.330 & 4.87 & 5.97 & 0.073 & 0.642 & 1898 & 568 & 86.8 & 102 & 0.0146 \\
\hline Diameter $(\mathrm{km})$ & 4879 & 12.104 & 12.756 & 3475 & 6792 & 142.984 & 120.536 & 51.118 & 49.528 & 2370 \\
\hline Density $\left(\mathrm{km} / \mathrm{m}^{3}\right)$ & 5427 & 5243 & 5514 & 0.073 & 3933 & 1326 & 687 & 1271 & 1638 & 2095 \\
\hline Gravity $\left(\mathrm{m} / \mathrm{s}^{2}\right)$ & 3.7 & 8.9 & 9.8 & 3475 & 3.7 & 23.1 & 9.0 & 8.7 & 11.0 & 0.7 \\
\hline Escape Velocity $(\mathrm{km} / \mathrm{s})$ & 4.3 & 10.4 & 11.2 & 3340 & 5.0 & 59.5 & 35.5 & 21.3 & 23.5 & 1.3 \\
\hline Rotation Period (hours) & 1407.6 & -5832.5 & 23.9 & 1.6 & 24.6 & 9.9 & 10.7 & -17.2 & 16.1 & -153.3 \\
\hline Length of Day (hours) & 4222.6 & 2802.0 & 24.0 & 2.4 & 24.7 & 9.9 & 10.7 & 17.2 & 16.1 & 153.3 \\
\hline Distance from Sun $\left(10^{6} \mathrm{~km}\right)$ & 57.9 & 108.2 & 149.6 & 655.7 & 227.9 & 778.6 & 1433.5 & 2872.5 & 4495.1 & 5906.4 \\
\hline Perihelion $\left(10^{6}\right)$ & 46.0 & 107.5 & 147.1 & 708.7 & 206.6 & 740.5 & 1352.6 & 2741.3 & 4444.5 & 5536.8 \\
\hline Aphelion $\left(10^{6} \mathrm{~km}\right)$ & 69.8 & 108.9 & 152.1 & 0.384 & 249.2 & 816.6 & 1514.5 & 3003.6 & 4545.7 & 7375.9 \\
\hline Orbital Period (days) & 88.0 & 224.7 & 365.2 & 0.363 & 687.0 & 4331 & 10.747 & 30.589 & 59.800 & 90.560 \\
\hline Orbital Velocity $(\mathrm{km} / \mathrm{s})$ & 47.4 & 35.0 & 29.8 & 0.406 & 24.1 & 13.1 & 9.7 & 6.8 & 5.4 & 4.7 \\
\hline Orbital Inclination (degree) & 7.0 & 3.4 & 0.0 & 27.3 & 1.9 & 1.3 & 2.5 & 0.8 & 1.8 & 17.2 \\
\hline Orbital Eccentricity & 0.205 & 0.007 & 0.017 & 1.0 & 0.094 & 0.049 & 0.057 & 0.046 & 0.011 & 0.244 \\
\hline Obliquity to Orbit (degree) & 0.034 & 177.4 & 23.4 & 5.1 & 25.2 & 3.1 & 26.7 & 97.8 & 28.3 & 122.5 \\
\hline Mean Temperature & 167 & 464 & 15 & -20 & -65 & -110 & -140 & -195 & -200 & -225 \\
\hline Number of Moon & 0 & 0 & 1 & 0 & 2 & 79 & 82 & 27 & 14 & 5 \\
\hline
\end{tabular}

\section{Results and Discussion}

In this section, the results of DEMATEL, TOPSIS and VIKOR methods and the results of TOPSIS and VIKOR methods applied using equal weight are given.

\subsection{DEMATEL Result}

Step 1: Using the binary comparison scale in Table 2, it was determined to what extent one criterion affected another.

Step 2: Given values are then placed in the matrix (Equation 1) and an asymmetric matrix with diagonals "0" is obtained.

Step 3: Once the direct relationship matrix is obtained, the largest and column sum of each row is found as shown in Equation 2. Then, the normalized direct relationship matrix $(\mathrm{C})$ is formed by dividing each element of the matrix by the value "s" as shown in Equation 3.

Step 4: By using the formula in Equation 4, the total relation matrix (F) is obtained.

Step 5: In this step, the total relationship matrix (F) was determined to determine the affecting and affected factor groups and to calculate their net effect degrees, and the row $\left(D_{i}\right)$ and column $\left(R_{i}\right)$ totals were found.

Step 6: At this stage, the threshold value of the matrix is determined. Then the scatter plot for the effect is drawn and criteria above the threshold were determined as affecting, the situation where any criterion affects it is also shown in the graphic.

The threshold value was found to be 0.15088539 . Criteria above this value were effectively identified and the situation affected by any criteria is shown in Figure 1.

Based on Equation 2, the sum of $i$ columns in the matrix $\mathrm{S}$ created (R) is expressed as the sum of rows in the $\mathrm{S}$ matrix (D), and using the D- R and D + R values, the level of influence of each criterion on the others and the level of relationship with the others are determined. Criteria with negative values for $\mathrm{D}-\mathrm{R}$ value were affected more than other criteria. These criteria, which are considered to have lower priority, are named buyers. C17, C14, C10, C11, C9, C16, $\mathrm{C} 15, \mathrm{C} 5, \mathrm{C} 13$ criteria were affected more than other criteria. On the other hand, D + R values show the relationship between each criterion and other criteria, and criteria with a high $\mathrm{D}+\mathrm{R}$ value are more related to other criteria, while low ones are less related to others. C12 and C13 criteria are criteria with high D + R values and are more related to other criteria.

Step 7: Equation 5 is used to obtain the criterion weights.

Step 8: Then each weight is divided by the sum of the weights in Equation 6 and the weights of the criteria are found (Table 4). 


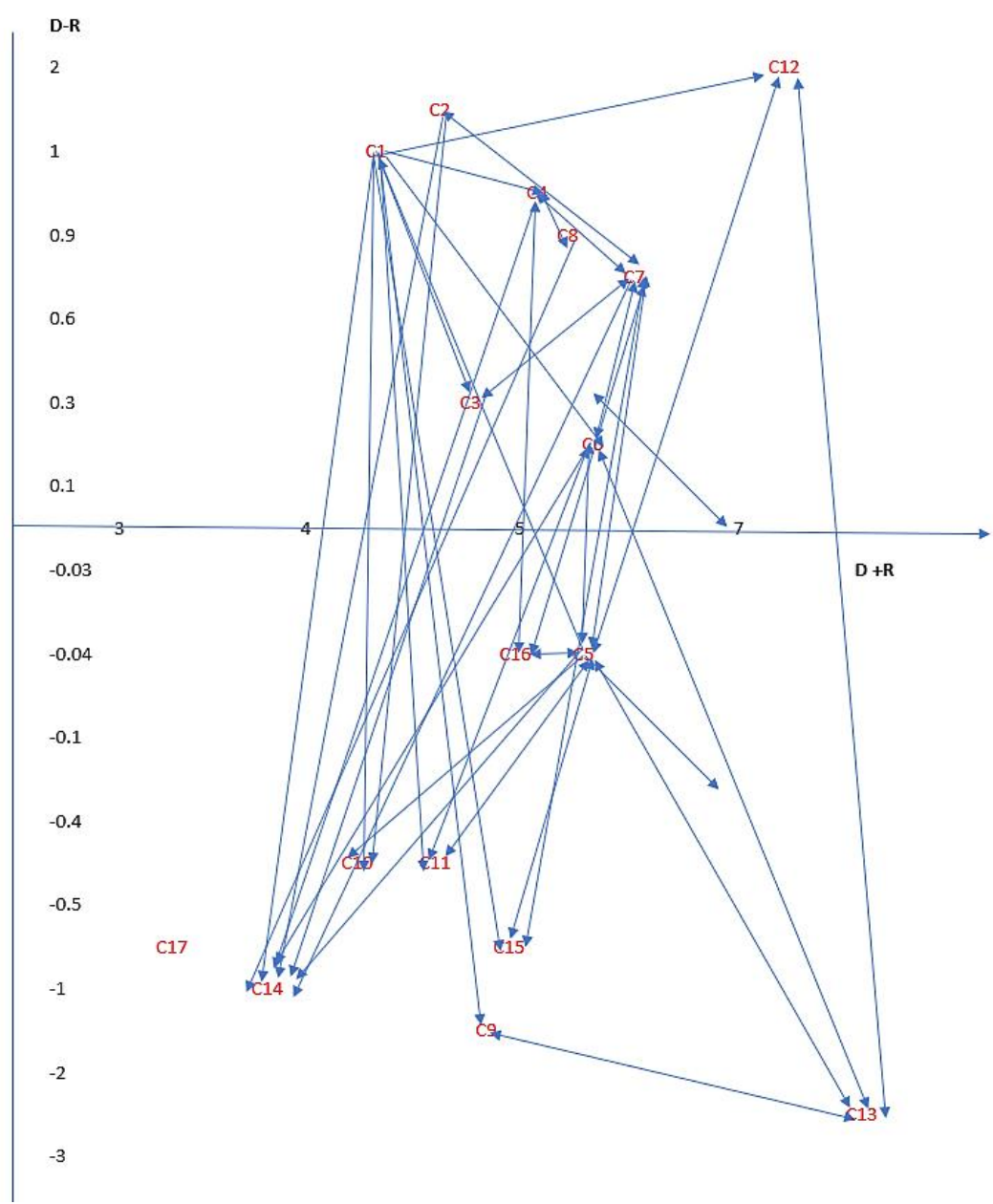

Figure 1. Effect-Direction Graph Diagram Result in DEMATEL

Table 4. Criteria weights using DEMATEL

\begin{tabular}{cccccccc}
\hline & & Weight & Criteria & & & Weight & Criteria \\
\hline 1 & C13 & 0.090 & Orb. inclination & 10 & $\mathrm{C} 16$ & 0.054 & Mean temperatures \\
2 & $\mathrm{C} 12$ & 0.086 & Orb. velocity & 11 & $\mathrm{C} 15$ & 0.054 & Obliquity to orbit \\
3 & $\mathrm{C} 7$ & 0.067 & Length of day & 12 & $\mathrm{C} 3$ & 0.053 & Density \\
4 & $\mathrm{C} 8$ & 0.062 & Distance from Sun & 13 & $\mathrm{C} 11$ & 0.052 & Orb. period \\
5 & $\mathrm{C} 4$ & 0.061 & Gravity & 14 & $\mathrm{C} 1$ & 0.051 & Mass \\
6 & $\mathrm{C} 5$ & 0.060 & Escape velocity & 15 & $\mathrm{C} 10$ & 0.048 & Aphelion \\
7 & $\mathrm{C} 6$ & 0.060 & Rotation period & 16 & $\mathrm{C} 14$ & 0.046 & Orb.eccentricity \\
8 & $\mathrm{C} 9$ & 0.056 & Perihelion & 17 & $\mathrm{C} 17$ & 0.036 & Number of moons \\
9 & $\mathrm{C} 2$ & 0.055 & Diameter & & & & \\
\hline
\end{tabular}

As can be seen in Table 4, the criterion with the highest weight is the orbital inclination. Orbital velocity is the criterion with the second highest weight and is ranked third in importance in the day length criterion of the planet. As a result of the DEMATEL technique that is applied, the criterion with the lowest weight is also determined. For a planet to be habitable, it is determined that the number of moons has the lowest weight, and this criterion is followed by orbital eccentricity and aphelion criteria, respectively.

\subsection{TOPSIS Result}

Step 1: At this stage, the purpose of the problem and the evaluation criteria were determined. Among the seventeen criteria, mass, escape velocity, rotation period, length of distance, distance from sun, aphelion, orbital inclination, orbital eccentricity, and obliquity to orbit and number of moons were determined as cost criteria. Among the seventeen criteria, diameter, gravity, density, perihelion, orbital period, orbital velocity, mean temperature were determined as benefit criteria. 
Step 2: Decision matrix (Equation 7) is created.

Step 3: Normalization is done according to the benefit criterion (Equation 9) and the cost criterion (Equation 10). The normalized matrix (Equation 8) is created.

Step 4: Weighting the normal matrix (Equation 11) creates the V matrix.

Step 5: While determining the ideal solution values, action was taken in line with the purpose of the problem. Equation 12 is used for positive ideal solutions and Equation 13 is used for negative ideal solutions.

Step 6: The separation measures of the alternatives were calculated using Equations 14 and 15.

Step 7: Using Equation 16, the approximation to the ideal solution is calculated.

Using the TOPSIS approach that includes the weights obtained by DEMATEL, it is determined that Earth is the first, Venus is the second and Mercury is the third habitable planet among others. The planets that are not suitable for life are found as Pluto, Saturn and Jupiter, respectively (Table 5).

Table 5. Ranking by TOPSIS

\begin{tabular}{ccc}
\hline Score & Rank & Planet \\
\hline 0.410028 & 10 & Pluto \\
0.498498 & 9 & Moon \\
0.509996 & 8 & Saturn \\
0.515575 & 7 & Uranus \\
0.524425 & 6 & Jupiter \\
0.535503 & 5 & Neptune \\
0.564921 & 4 & Mars \\
0.573476 & 3 & Mercury \\
0.575747 & 2 & Venus \\
0.612021 & 1 & Earth \\
\hline
\end{tabular}

\subsection{VIKOR Result}

Step 1: Once the criteria weights are determined, the best and worst values are determined according to Equation 17 to evaluate alternatives.

Step 2: The decision problem consisting of $M$ alternative and $n$ criteria is transformed into a $m \times n$ type $R$ normalization matrix according to Equation 18.

Step 3: Using Equation 19, the normalized matrix is multiplied by the criterion weights.

Step 4: $S_{i}$ is the i. the mean score for the alternative, $R_{i}$ represents the worst score, Equations 20 and 21 are used to calculate the values of $S_{i}$ and $R_{i}$.

Step 5: In this step, $Q_{i}$ is calculated using the values of $S_{i}$ and $R_{i}$ calculated earlier (Equation 23). These values are shown in Table 6.

Step 6: The listed alternatives and conditions have been checked. For Condition 1, Equations 24 and 25 are used. Condition 1 is satisfied. For Condition 2, the values, $A^{1}$ and $A^{2}$ are placed in the list. Condition 2 is not satisfied.

Table 6. Ranking by VIKOR

\begin{tabular}{cccccc}
\hline $\boldsymbol{S}_{\boldsymbol{j}}$ & $\boldsymbol{R}_{\boldsymbol{j}}$ & $\boldsymbol{Q}_{\boldsymbol{j}}$ & $\boldsymbol{S}_{\boldsymbol{j}}$ & $\boldsymbol{R}_{\boldsymbol{j}}$ & $\boldsymbol{Q}_{\boldsymbol{j}}$ \\
\hline 0.335 & 0.054 & 0.005 & Earth & Mars & Earth \\
0.375 & 0.054 & 0.125 & Venus & Earth & Mars \\
0.390 & 0.060 & 0.181 & Mercury & Mercury & Mercury \\
0.408 & 0.064 & 0.248 & Mars & Jupiter & Venus \\
0.439 & 0.067 & 0.384 & Neptune & Venus & Jupiter \\
0.479 & 0.070 & 0.502 & Jupiter & Saturn & Saturn \\
0.482 & 0.075 & 0.512 & Moon & Uranus & Neptune \\
0.483 & 0.078 & 0.551 & Uranus & Neptune & Uranus \\
0.498 & 0.086 & 0.680 & Saturn & Moon & Pluto \\
0.627 & 0.090 & 0.697 & Pluto & Pluto & Moon \\
\hline
\end{tabular}


As a result of the numerical table formed after the formulation processes of the VIKOR technique, there are two conditions at the last stage of the VIKOR technique. The results are determined according to the fulfilment or nonrealization of these conditions. In the problem of the most habitable planet, it has been determined that the first condition is fulfilled and the second condition is not suitable. According to the VIKOR method, Earth ranked first, Mars ranked second, and Mercury ranked third in terms of the most habitable planets.

In addition to the weighted VIKOR and TOPSIS results, the weights of the criteria are considered equally, and the TOPSIS and VIKOR techniques are applied again. The new results are given in Tables 7 and 8.

Table 7. TOPSIS results with equal weights

\begin{tabular}{ccc}
\hline Score & Rank & Planet \\
\hline 0.443746 & 10 & PLUTO \\
0.491344 & 9 & SATURN \\
0.499698 & 8 & JUPITER \\
0.511624 & 7 & URANUS \\
0.523821 & 6 & MOON \\
0.548625 & 5 & NEPTUNE \\
0.556278 & 4 & MARS \\
0.559077 & 3 & MERCURY \\
0.575626 & 2 & VENUS \\
0.600253 & 1 & EARTH \\
\hline
\end{tabular}

It is found that the top three planets (Earth, Venus, and Mercury) in the TOPSIS-DEMATEL solution are also in the top three in the equally weighted solution. Only Saturn, Jupiter, and the Moon are replaced within the planets. In the VIKOR method, with equal criterion weights, the best alternative could not be determined due to the unsatisfied conditions.

Table 8. VIKOR results with equal weights

\begin{tabular}{cccccc}
\hline $\boldsymbol{S}_{\boldsymbol{j}}$ & $\boldsymbol{R}_{\boldsymbol{j}}$ & $\boldsymbol{Q}_{\boldsymbol{j}}$ & $\boldsymbol{S}_{\boldsymbol{j}}$ & $\boldsymbol{R}_{\boldsymbol{j}}$ & $\boldsymbol{Q}_{\boldsymbol{j}}$ \\
\hline 0.337250138 & 0.056262 & 0.256978 & Earth & Uranus & Neptune \\
0.367726761 & 0.056689 & 0.278674 & Venus & Neptune & Uranus \\
0.396909493 & 0.058395 & 0.45714 & Mercury & Mars & Earth \\
0.410157042 & 0.058604 & 0.554519 & Mars & Earth & Mars \\
0.428857898 & 0.058824 & 0.557769 & Neptune & Venus & Venus \\
0.459223337 & 0.058824 & 0.613085 & Moon & Moon & Mercury \\
0.484267401 & 0.058824 & 0.731202 & Uranus & Mercury & Moon \\
0.500513686 & 0.058824 & 0.809469 & Jupiter & Jupiter & Jupiter \\
0.512581164 & 0.058824 & 0.832343 & Saturn & Saturn & Saturn \\
0.601030182 & 0.058824 & 1 & Pluto & Pluto & Pluto \\
\hline
\end{tabular}

When the space problems in the literature are examined, no study has been found with multi-criteria decision making methods. For this reason, it is thought that this study will contribute to the field by creating an alternative to the existing methods. Considering the factors that are effective in choosing the most habitable planet in future studies on the subject, the continuity of studies can be ensured.

\section{Conclusion}

In this study, the TOPSIS and VIKOR methods were used to evaluate habitable planets, and the results were compared. The DEMATEL method was used to determine the criterion weights. According to the DEMATELTOPSIS methods, Earth ranked first, Venus ranked second, and Mercury ranked third in the ranking of the most habitable planets. With the DEMATEL-VIKOR method, Earth ranked first, Mars ranked second, and Mercury ranked third in the list of habitable planets. The TOPSIS and VIKOR methods were also applied by taking the criterion weights equally. According to the TOPSIS method, Earth is in the first place, Venus is in the second, and Mercury is in the third place. Since the first and second conditions could not be met in the VIKOR method with equal criteria weights, the best alternative could not be determined. After this study, MCDM methods can be used to analyse nutrients that can be grown on planets. These methods can also be applied to the selection of astronauts with different characteristics to be sent to space. 


\section{Declarations}

\subsection{Author Contributions}

Conceptualization, E.O.; formal analysis, G.G. and G.D.; investigation, G.G., G.D. and E.O.; writing-original draft preparation, G.G., G.D. and E.O.; writing - review and editing, G.G., G.D. and E.O.; visualization, G.G. and G.D. All authors have read and agreed to the published version of the manuscript.

\subsection{Data Availability Statement}

The data presented in this study are available in article.

\subsection{Funding}

The authors received no financial support for the research, authorship, and/or publication of this article.

\subsection{Declaration of Competing Interest}

The authors declare that they have no known competing financial interests or personal relationships that could have appeared to influence the work reported in this paper.

\section{References}

[1] Yücenur, G. N., \& Subaşı, A. S. (2019). An integrated solution for space shuttle launching ramp. Aircraft Engineering and Aerospace Technology, 91(7), 1051-1057. doi:10.1108/AEAT-10-2018-0257.

[2] Shieh, J. I., Wu, H. H., \& Huang, K. K. (2010). A DEMATEL method in identifying key success factors of hospital service quality. Knowledge-Based Systems, 23(3), 277-282. doi:10.1016/j.knosys.2010.01.013.

[3] Abbasi, M., Hosnavi, R., \& Tabrizi, B. (2013). Application of Fuzzy DEMATEL in Risks Evaluation of Knowledge-Based Networks. Journal of Optimization, 2013, 1-7. doi:10.1155/2013/913467.

[4] Ada, E., Kazançoğlu, Y., \& Aksoy, M. (2011). Evaluation of factors affecting flexible production systems using fuzzy DEMATEL method. Proceedings of 11. Production Research Symposium, 722-731.

[5] Aksakal, E., \& Dağdeviren, M. (2010). An integrated approach to personnel selection problem with ANP and DEMATEL methods. Gazi University Journal of Engineering and Architecture Faculty, 25(4), 905-913.

[6] Dey, S., Kumar, A., Ray, A., \& Pradhan, B. B. (2012). Supplier selection: Integrated theory using DEMATEL and quality function deployment methodology. Procedia Engineering, 38, 2111-2116. doi:10.1016/j.proeng.2012.06.253.

[7] Karaatlı, M., Ömürbek, N., Işık, E., \& Yılmaz, E. (2016). DEMATEL and fuzzy TOPSIS application in performance appraisal. Ege Academic Review, 16(1), 49-64.

[8] Ömürbek, V., \& Kınay, B. (2013). Financial performance assessment with TOPSIS method in airline transport sector. Süleyman Demirel University Journal of Economics and Administrative Sciences, 18(3), 343-363.

[9] Uygurtürk, H., \& Korkmaz, T. (2012). The TOPSIS multi-criteria decision making of financial performance method: An application on basic metal industry enterprises. Eskişehir Osmangazi University Journal of the Faculty of Economics and Administrative Sciences, 7(2), 95-115.

[10] Yurdakul, M., \& İç, Y. T. A. (2003). Case study using TOPSIS method for performance measurement and analysis of Turkish automotive companies. Gazi University Journal of Engineering and Architecture Faculty, 18(1), 1-18.

[11] Boran, F. E., Genç, S., Kurt, M., \& Akay, D. (2009). A multi-criteria intuitionistic fuzzy group decision making for supplier selection with TOPSIS method. Expert Systems with Applications, 36(8), 11363-11368. doi:10.1016/j.eswa.2009.03.039.

[12] Tirmıkçığlu Ç, N., (2010). Fuzzy TOPSIS method in establishment selection and an application in banking sector, Karamanoğlu Mehmetbey University Journal of Social and Economic Research, 18(12), 37-45.

[13] Kahriman, A., Oztokatli, M., \& Das, G. S. (2015). Selection of a communication satellite manufacturer using MCDM methods. RAST 2015 - Proceedings of 7th International Conference on Recent Advances in Space Technologies, 347-351. doi:10.1109/RAST.2015.7208368.

[14] Tadić, S., Zečević, S., \& Krstić, M. (2014). A novel hybrid MCDM model based on fuzzy DEMATEL, fuzzy ANP and fuzzy VIKOR for city logistics concept selection. Expert Systems with Applications, 41(18), 8112-8128. doi:10.1016/j.eswa.2014.07.021.

[15] Hsu, C. H., Wang, F. K., \& Tzeng, G. H. (2012). The best vendor selection for conducting the recycled material based on a hybrid MCDM model combining DANP with VIKOR. Resources, Conservation and Recycling, 66, $95-111$. doi:10.1016/j.resconrec.2012.02.009. 
[16] Görener, A. (2011). Selection of ERP software with integrated ANP-VIKOR approach. Journal of Aviation and Space Technologies, 5(1), 97-110.

[17] Dinçer, H., \& Görener, A. (2011). AHP - VIKOR and AHP - TOPSIS approaches in performance evaluation: An application in the service industry. Sigma Journal of Engineering and Science, 29, 244-260.

[18] Wu, W. W., \& Lee, Y. T. (2007). Developing global managers' competencies using the fuzzy DEMATEL method. Expert Systems with Applications, 32(2), 499-507. doi:10.1016/j.eswa.2005.12.005.

[19] Li, H., Wang, W., Fan, L., Li, Q., \& Chen, X. (2020). A novel hybrid MCDM model for machine tool selection using fuzzy DEMATEL, entropy weighting and later defuzzification VIKOR. Applied Soft Computing, 91, 106207. doi:10.1016/j.asoc.2020.106207

[20] Chen, Y., Ran, Y., Huang, G., Xiao, L., \& Zhang, G. (2021). A new integrated MCDM approach for improving QFD based on DEMATEL and extended MULTIMOORA under uncertainty environment. Applied Soft Computing, 105, 107222. doi:10.1016/j.asoc.2021.107222

[21] Karaoğlan, S. (2016). Selection of an outsourcing provider with DEMATEL and VIKOR methods: Hotel business example. Akademik Bakış Dergisi, 55, 9-24.

[22] Hwang CL., Yoon K. (1981) Methods for Multiple Attribute Decision Making. In: Multiple Attribute Decision Making. Lecture Notes in Economics and Mathematical Systems, 186. Springer, Berlin, Heidelberg, Germany. doi:10.1007/978-3-64248318-9_3.

[23] Kuru, A., \& Akin, B. (2012). Entegre Yönetim Sistemlerinde Çok Kriterli Karar Verme Tekniklerinin Kullanımına Yönelik Yaklaşımlar Ve Uygulamaları. Öneri Dergisi, 10(38), 129-144.

[24] Opricovic, S., \& Tzeng, G. H. (2004). Compromise solution by MCDM methods: A comparative analysis of VIKOR and TOPSIS. European Journal of Operational Research, 156(2), 445-455. doi:10.1016/S0377-2217(03)00020-1.

[25] Kim, M. S. (2019). Deliberative collaboration in learning-by-designing multimodal modeling activities. Interactive Learning Environments, 29(8), 1319-1338. doi:10.1080/10494820.2019.1627666.

[26] Williams, D. (2015). Planetary Fact Sheet - Metric. In NASA Goddard Space Flight Center. Available online: http://nssdc.gsfc.nasa.gov/planetary/factsheet/ (accessed on February 2021). 